\title{
REVISIÓN
}

\section{Bacterias del ácido láctico en la fermentación de aceitunas de mesa}

\author{
Por M. C. Durán Quintana, C. Romero Barranco, P. García García, M. Brenes Balbuena \\ y A. Garrido Fernández*
}

Instituto de la Grasa. Apartado 1078. 41012 - Sevilla

\section{RESUMEN}

Bacterias del ácido láctico en la fermentación de aceitunas de mesa.

El trabajo hace una revisión de las características del desarrollo de las bacterias ácido lácticas (BAL) en la elaboración de los tres tipos de aceitunas de mesa más importantes en el comercio internacional. El único proceso espontáneo típicamente láctico es el de las verdes estilo español. La presencia de las BAL en la etapa de conservación de las aceitunas tipo negras y en la fermentación de las negras naturales depende de diversos factores tales como variedad, concentración de cloruro sódico, corrección inicial del pH, etc. El conocimiento de las condiciones en las que se produce el crecimiento natural puede permitir un mejor control microbiológico y la utilización eficaz de cultivos iniciadores en dichas fermentaciones.

PALABRAS-CLAVE: Aceituna de mesa - Bacterias del ácido láctico - Fermentación - Revisión (artículo).

\section{SUMMARY}

Lactic acid bacteria in table olive fermentations.

The paper reviews the characteristics for the lactic acid bacteria (LAB) growth in the three main table olive types in the international trade. The only typical spontaneous lactic process is that followed in the Spanish-style green olives. The growth of LAB throughout storage in brine of ripe olives and fermentation of naturally ripe (black) olives depends on various factors such as olive cultivars, sodium chloride concentration, initial $\mathrm{pH}$ correction, etc. The knowledge of the spontaneous growth conditions is essential for a better microbiological control and the efficient use of starter cultures in these fermentations.

KEY-WORDS: Fermentation - Lactic acid bacteria - Review (paper) - Table olive.

\section{INTRODUCCIÓN}

Las aceitunas de mesa constituyen, sin lugar a dudas, el producto vegetal fermentado más importante del mundo occidental, alcanzándose, al iniciarse la década de los 90 , una producción anual superior a 1.000.000 toneladas (Anónimo, 1994). La previsión del Consejo Oleícola Internacional indica una tendencia suave (alrededor de un $2 \%$ anual) de crecimiento para un futuro próximo, tanto en la elaboración como en el consumo. En estos momentos, la Unión Europea (UE) es el principal fabricante, con unas cifras que representan entre el 40 y $50 \%$ del total. Dentro de ella, destaca la contribución española, estimada en torno a las 250.000 toneladas por campaña. Las presentaciones de mayor aceptación son las derivadas de las aceitunas verdes estilo sevillano o español, que han mostrado una evolución al alza durante los últimos decenios. Las aceitunas tipo negras, que habían sido características de USA desde principios de siglo, se han extendido a otros países, principalmente España, y han experimentado una clara expansión en el mismo período. Por el contrario, la preparación de las aceitunas negras naturales, que fueron las más importantes hasta los años setenta, ha ido lentamente descendiendo, incluso en los países en los que constituían una arraigada tradición.

En estos momentos, el Sector, a pesar de gozar aparentemente de una sólida posición dentro del conjunto de la industria agro-alimentaria mundial, atraviesa un período de cierta crisis. Esta se aprecia de manera clara en la estabilización, o incluso disminución, de las producciones. A escala de la UE, los problemas más acuciantes parecen ser derivados de la política agraria de ésta y a fenómenos coyunturales; pero, no hay que olvidar que los aspectos científicos y tecnológicos pueden jugar también un papel importante para mejorar la situación. Por ejemplo, una campaña basada en el valor nutricional de la aceituna de mesa, y en su pertenencia desde la más remota antigüedad a la saludable dieta mediterránea, es posible que tuviera una repercusión muy favorable en el aumento de su consumo, tanto en los países productores como en aquellos sólo importadores.

Asimismo, conviene recordar que la fermentación de la práctica totalidad de las aceitunas de mesa transcurre en estos momentos aún de forma espontánea y que el seguimiento del proceso se hace principalmente basándose en análisis fisicoquímicos. El 
control microbiológico es, por tanto, muy escaso. Es más, la propia tecnología actual hace muy difícil esa operación. Los utensilios, interiores de los fermentadores, la abertura superior de los mismos, etc., permiten un importante e incontrolado aporte microbiano desde el ambiente exterior. Sin embargo, es evidente que esta situación es desfavorable para la consecución de calidades homogéneas y homologables. En opinión de los autores, es necesario realizar un esfuerzo por parte de los industriales y de los investigadores para poder llegar a un mayor dominio sobre estos aspectos. Un primer paso ineludible para dirigir estas fermentaciones, es conocer con detalle el papel de las bacterias ácido lácticas en las diferentes preparaciones. A partir de ello, se podrá favorecer su crecimiento con la utilización de cultivos iniciadores y diseñar las modificaciones más apropiadas de las condiciones de trabajo y de los fermentadores del futuro.

\section{PRINCIPALES FORMAS DE PREPARACIÓN DE ACEITUNAS DE MESA}

Bajo el nombre genérico de aceitunas de mesa se engloba una gran diversidad de productos comerciales. Con objeto de sistematizar sus denominaciones, estas incluyen una serie de términos que permiten la correcta e inequívoca identificación de cada una de ellas. El más amplio corresponde a los llamados tipos. La Norma cualitativa unificada aplicable a las ACEITUNAS de MESA en el comercio internacional (COI, 1981) contempla tres: verdes, color cambiante y negras, atendiendo al estado de madurez de la materia prima. Sin embargo, la Reglamentación técnico sanitaria para la elaboración, circulación, y venta de aceitunas de mesa española (Presidencia del Gobierno, 1983), añade uno más a los anteriores, el tipo negras, basado en la forma peculiar de conseguir el color marrón a negro de este producto final (los frutos se recogen verdes o de color cambiante y la tonalidad oscura se obtiene por oxidación). En cualquier caso, los tres tipos más importantes son: aceitunas verdes, negras naturales y tipo negras (consideradas dentro de las de color cambiante por el COI).

Otra característica a tener en cuenta es la manera de eliminar el principio amargo de los frutos, o disminuir su contenido, de forma que sean aptos para el consumo humano. Existen principalmente dos sistemas: mediante tratamiento alcalino, con lo que en la definición debe incluirse el término «tratado» o «aderezado»; o simplemente por dilución en la salmuera o líquido en el que se sumergen los frutos, en cuyo caso se llaman «al natural». En el último caso lo más frecuente es que no se haga mención alguna a este aspecto. Otros calificativos se refieren al medio de conservación (salmuera, en seco, etc.) o a la forma de presentación (enteras, rodajas, etc.), que, en general, afectan a la aceituna ya fermentada. Combinando las dos primeras variables, se obtienen las tres elaboraciones de mayor aceptación. Son las siguientes:

\section{a) Aceitunas verdes aderezadas en salmuera (AV), estilo sevillano o español}

Son las preparadas a partir de frutos que han alcanzado su pleno desarrollo, aunque conservan todavía el color verde. Se endulzan mediante un tratamiento con una solución de hidróxido sódico y, después de una etapa de lavado con agua o con agua acidulada, se introducen en una salmuera del 10-12\% (peso/volumen, en adelante), de $\mathrm{NaCl}$. En ella experimentan el posterior proceso fermentativo.

\section{b) Aceitunas negras por oxidación o tipo negras (TP)}

El momento de la recolección es diverso: totalmente verdes o cuando presentan una cierta tonalidad rojiza o púrpura en la piel. De hecho, las estadísticas del Consejo Oleícola Internacional, las incluyen en las de color cambiante. Una vez lavadas y clasificadas (en algunos países productores) se colocan en salmuera o cualquier otra solución, en la que tiene lugar el desarrollo de microorganismos, en espera de la etapa de ennegrecimiento.

\section{c) Aceitunas negras naturales (ANN)}

Se recogen cuando los frutos han alcanzado su total madurez y la pulpa presenta una tonalidad púrpura o marrón oscura en la mayoría de ellos. Las aceitunas pueden someterse, al recibirse del campo, a un calibrado opcional. A continuación, se lavan y se colocan en salmuera de concentración variable, según las costumbres de los diversos países. En ella permanecen hasta que han perdido la mayor parte de sabor amargo y experimentan la correspondiente fermentación.

\section{FACTORES CONDICIONANTES PARA EL DESARROLLO DE BACTERIAS ÁCIDO LÁCTICAS (BAL) EN LA FERMENTACIÓN DE ACEITUNAS}

El crecimiento de BAL en la fermentación de aceitunas depende de muy diversos factores. Sin embargo, la forma de reducir su intenso sabor amargo, debido a las propiedades de la oleuropeina y otros polifenoles que forman parte de su composición, es fundamental. Los frutos tratados con una solución de hidróxido sódico («lejía»), muestran siempre una disposición muy favorable. En cambio, los endulzados mediante dilución, o cuando la lejía no penetra ade- 
cuadamente, suelen presentar dificultades más o menos importantes e, incluso, en numerosas ocasiones, inhiben completamente el desarrollo de las BAL. Así, pues, el factor más determinante es la presencia de polifenoles; otros condicionantes son la concentración de sal, variedad, temperatura, azúcares disponibles, etc. Se comentarán por separado a continuación.

\section{A) Efecto de los polifenoles}

Etchells et al. (1966) encontraron que las aceitunas de la variedad Manzanilla no experimentaban una fermentación láctica cuando se colocaban directamente en salmuera, incluso añadiéndoles un cultivo puro de Lactobacillus plantarum. En cambio, cuando se sometían a una solución de hidróxido sódico o a un tratamiento previo con calor $\left(74^{\circ} \mathrm{C}\right.$ durante 3 minutos) las BAL crecían de forma vigorosa. Este diferente comportamiento lo atribuyeron a la existencia en el fruto de un compuesto inhibidor de las BAL, que se destruía al aplicar los procesos anteriores. También Juven et al. (1968 a) informaron de una mejora de la fermentación láctica después de sumergir las aceitunas en lejía caliente durante un tiempo corto. Igualmente, imputaron este fenómeno a la destrucción del mencionado inhibidor, que parecía localizarse en las zonas próximas a la piel (Samish et al. 1968). Las primeras evidencias de la existencia de esas sustancias la aportaron Fleming y Etchells (1967) y Fleming et al. (1969). En investigaciones posteriores, dichos autores encontraron que el principio amargo, oleuropeína, no era, precisamente, el compuesto más activo en este aspecto, en contra de lo que había sugerido Juven et al. (1968 b). Para aquellos resultó evidente que los derivados de la hidrólisis de la oleuropeína, la aglucona y el ácido elenólico, presentaban una mayor actividad frente a las BAL (Fleming et al., 1973; Walter et al., 1973). Estas conclusiones contrastan con otros resultados que han demostrado que la oleuropeína al $0,4 \%(p / v)$, concentración a la que aproximadamente se encuentra en las salmueras, tiene un efecto bactericida inmediato en un medio de cultivo sintético frente a $L b$. plantarum. Dicha actividad desaparece si se procede a una alcalinización con $\mathrm{NaOH}$ y persiste aún después de calentar (Ruiz Barba, 1991; Ruiz Barba et al. 1990 y 1991). Diversos compuestos derivados de la oleuropeína u otros fenoles presentan asimismo efecto inhibidor, habiendo sido el hidroxitirosol el que lo ha mostrado de forma más destacada. Las mezclas binarias de todos ellos indicaron respuestas asimismo aditivas (Ruiz Barba et al., 1993).

Finalmente, un trabajo realizado por Rózes y Peres (1996) ha encontrado que la oleuropeína no es por sí misma inhibidora de Lb. plantarum. En cambio, cuando se forma la aglucona, por la acción de la $\beta$-glucosidasa, se produce una rápida disminución de las células viables, que depende de la concentración de la aglucona y es especialmente importante en presencia de bajas concentraciones de azúcares, lo cual está también de acuerdo con lo encontrado por Garrido y Vaughn (1978). Sin embargo, la oleuropeína tuvo una acción bactericida muy acusada, que disminuyó a medida que la concentración de glucosa aumentaba, en presencia de sal (6\%).

El mecanismo de actuación de los polifenoles sobre las BAL ha sido estudiado en detalle por Juven et al. (1972) y Ruiz Barba et al. (1990). El primero encontró que dichas sustancias se adherían a la pared y provocaban la salida de una serie de compuestos del interior de las células hacia el líquido en el que estaban suspendidas. Este hecho se materializaba principalmente en la pérdida de iones $\mathrm{K}+$. El segundo de los autores ha descrito dos tipos de mecanismos. Uno de ellos consiste básicamente en la adsorción de los fenoles sobre las paredes celulares, cosa que se observa perfectamente al microscopio gracias a la fluorescencia de los mismos. Las células afectadas presentan una superficie irregular, con numerosos salientes o gránulos de diferentes tamaños y exhiben en su conjunto un aspecto rugoso. Estos síntomas se incrementan a medida que transcurre el período de incubación, desapareciendo casi completamente la pared celular al cabo de los 3-11 días. El segundo fenómeno encontrado fue la presencia de mesosomas en la mayoría de las células tratadas, que pierden su forma típica al cabo de unos 11 días y adquieren un aspecto esférico, parecido al de los protoplastos, con rotura, incluso, de muchas de ellas. Dichos autores explican este fenómeno, por la masiva unión de los fenoles a los grupos - $\mathrm{CO}$ y $-\mathrm{NH}$ libres de los pectidoglucanos de la pared celular. Ello causa la inestabilidad de la pared, especialmente en el «septum» de división donde los radicales libres son más abundantes. Un efecto combinado de ambos, causa la muerte de la bacteria. Ròzes y Peres (1996) parecen haber encontrado también otro efecto: la inhibición del mecanismo de descarboxilación del ácido málico a causa de la aglucona de la oleuropeína. Dicha acción se puede deber a interferencias causadas en el sistema de transporte del ácido málico, como resultado de la combinación de los fenoles con proteínas de la membrana, tal como se ha comentado antes.

Esta facilidad de reacción de los fenoles con proteínas puede ser la causa de las aparentes discrepancias entre los resultados de diversos experimentos descritos en la bibliografía. En algunos de ellos, las proteínas procedentes de los medios han podido interferir de una $u$ otra forma con los cultivos añadidos y falsear los resultados.

No obstante, a pesar de ese carácter inhibidor hacia las BAL, se ha informado de la existencia de cepas de $L b$. plantarum que poseen la capacidad de hidrolizar «in vitro» la oleuropeína e, incluso, su aglucona (Ciafardini et al., 1994). El mecanismo mediante el cual esto ocurre ha sido estudiado por Marsilio et al. (1996). Basados en estudios cinéticos, se ha apuntado la hipótesis de que dicha cepa hidrolice, en primer 
lugar, la oleuropeína, a través de la acción de una $\beta$ glucosidasa, lo que produce la aglucona correspondiente (que es un producto intermedio claramente observable). En un segundo paso, la aglucona se hidroliza mediante una esterasa, lo que da lugar al 2(3-3-dihidroxifenil) etanol, que ha podido ser igualmente identificado y cuantificado $y$, posiblemente, a ácido elenólico, que no ha sido encontrado. Sin embargo, esta capacidad de hidrólisis no significa que no exista paralelamente un efecto de inhibición debido a los productos resultantes, que pueden aumentar a medida que la reacción progresa. Aparentemente, un efecto de estas características ha sido encontrado por Ròzes y Peres (1996), tal como ya se ha apuntado.

\section{B) Concentración de sal y pH}

Son factores determinantes para el crecimiento de $B A L$, aunque, afortunadamente en este caso, controlables. Es un hecho incuestionable que concentraciones de $\mathrm{NaCl}$ superiores al $8 \%$ en las fermentaciones de aceitunas son prácticamente inhibidoras de las BAL. Balatsouras (1985) hizo una amplia selección de BAL procedentes de salmueras de todo tipo. De la distribución de los cultivos provenientes de AV con respecto a la tolerancia en sal (figura 1) se puede deducir que con una concentración de $\mathrm{NaCl}$ del $6 \%$ se produce ya una inhibición del $33,3 \%$ de las cepas; cuando la concentración se eleva al $7 \%$, el efecto alcanza el $50 \%$; al $8 \%$ sólo sobreviven alrededor del $10 \%$; y a partir del $9 \%$ ninguna. Por tanto, este parece ser el límite superior para el crecimiento de las BAL en aceitunas de dicho tipo. Los lactobacilos procedentes de ANN mostraron una tolerancia algo superior. Teniendo en cuenta que en otros productos, como por ejemplo pepinillos, se han descrito cepas más resistentes de estas bacterias, parece probable que, en el caso de las aceitunas, la presencia de oleuropeína y otros fenoles puede dar lugar a una cierta sinergia con la sal y contribuir a disminuir la resistencia de las mismas con respecto a ésta solamente, tal como han encontrado Ròzes y Peres (1996).

Bobillo y Marshall (1991) informaron, asimismo, que la presencia de sal disminuía la densidad de células, retardaba el consumo de glucosa y citrato y, finalmente, reducía la relación acetato/lactato producidos. Sin embargo, el efecto era diferente y dependía de la disponibilidad de oxígeno. En medio aeróbico, el principal metabolito producido por $L b$. plantarum era acetato, mientras que en medio anaerobio era lactato. En el transcurso de una incubación prolongada en condiciones aerobias se observó la producción de acetato a expensas del lactato formado durante las etapas previas y esta acumulación de acetato coincidía con una disminución de la concentración de citrato en anaerobiosis. La presencia de sal no sólo disminuyó la conversión de lactato en acetato sino que alteró el mecanismo metabólico de utilización del citrato y facilitó la utilización de una ruta alternativa, independiente del oxígeno, para la utilización del lactato, la cual daba, aparentemente, productos finales diferentes al acetato.

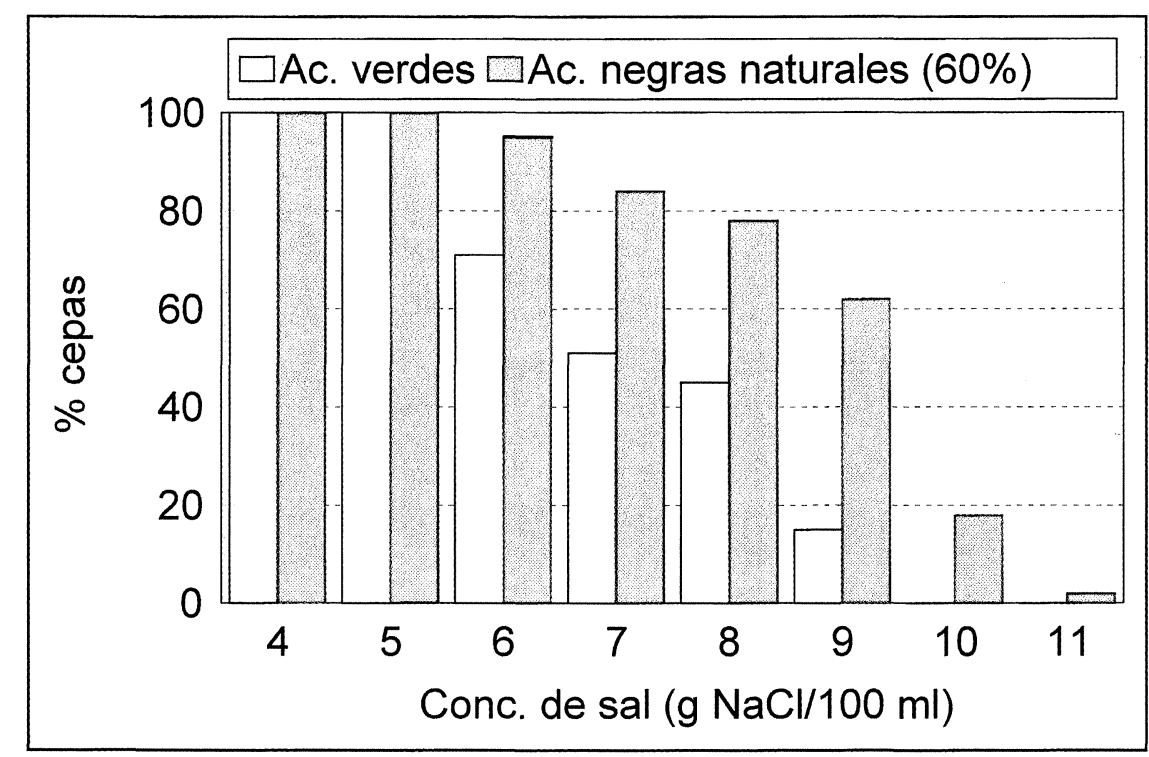

Figura 1

Tolerancia a la sal de cepas de Lactobacillus plantarum aisladas de salmueras de fermentación de aceitunas verdes estilo sevillano y negras naturales ( $60 \%$ de las muestras).

Tomado de Balatsouras et al. (1985) 
El efecto combinado del $\mathrm{pH}$ y sal también es apreciable en condiciones límites de glucosa (Bobillo y Marshall, 1992). Así, en medio aeróbico y en cultivo continuo, $\mathrm{Lb}$. plantarum alteró sus rutas metabólicas como respuesta a los cambios en el $\mathrm{pH}$ del medio. A medida que descendió el pH del medio disminuyó la proporción de acetato y L-lactato producidos, mientras que aumentó la cantidad de D-lactato. En estas condiciones, la formación de acetato y lactato continuó hasta niveles del $6 \%$ de $\mathrm{NaCl}$, pero, en presencia de sal, ya no se produjo acetato a valores de $\mathrm{pH}$ inferiores a 4,5. Todas estas influencias pueden ser de una gran trascendencia en cuanto a las cantidades finales de productos formados y, por tanto, para las características organolépticas finales obtenidas y la conservación del producto.

Tolerancias diversas al contenido de sal pueden estar relacionadas con características específicas de determinadas cepas de $L b$. plantarum. Así, la cepa $\mathrm{H} 4$ (no productora de bacteriocina) resultó ser más tolerante a la sal (8\%) que otra productora de ella, LPCO10, que sólo soportó el $6 \%$ posiblemente como una respuesta de la primera para su supervivencia frente a la segunda (Montaño et al., 1993).

Con respecto a la tolerancia al $\mathrm{pH}$, Balatsouras (1985) encontró que la mayoría de las cepas de $L b$. plantarum crecian bien entre valores de $\mathrm{pH}$ comprendidos entre 3,25 y 8,00 . Ninguna de ellas sobrevivía por encima de 8,50 y eran también muy pocas las que soportaban un $\mathrm{pH}$ muy ácido. El límite superior de acidez láctica soportada por los lactobacilos aislados de fermentaciones de aceitunas parece ser el $2 \%$, de acuerdo con el mismo autor (figura 2). Curiosamente, las cepas más resistentes a la acidez provinieron de los cultivos aislados de ANN, aunque las procedentes de AV presentaban, en general, tolerancias también muy elevadas (entre el 1,3 y 1,9\% de acidez).

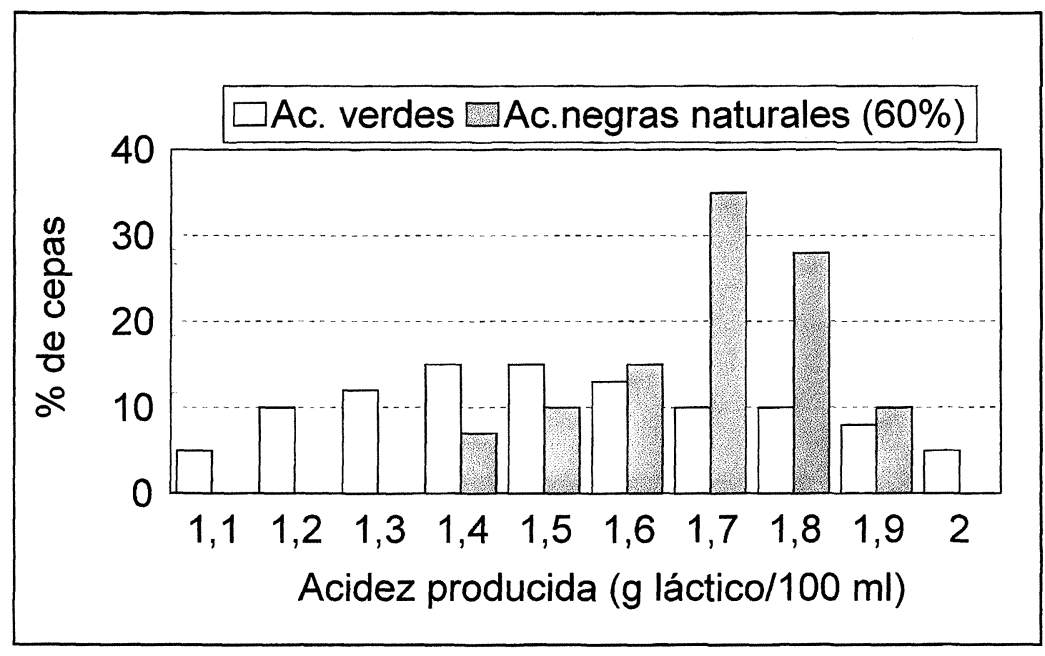

Figura 2

Producción de acidez de cepas de Lactobacillus plantarum aisladas de salmueras de fermentación de aceitunas verdes estilo sevillano y negras naturales (60\% de las muestras). Tomado de Balatsouras et al. (1985)

El mecanismo de resistencia de algunas bacterias lácticas al $\mathrm{pH}$ ha sido estudiado por McDonald et al. (1990). Los límites de pH en el interior de las células para Leuconostoc mesenteroides y $L b$. plantarum oscilaron entre 5,4 a 5,7 y 4,6 a 4,8, respectivamente, aunque a valores inferiores a 4,0 el crecimiento ya era difícil. El pH del interior descendía a medida que el del exterior también lo hacía, siguiendo comportamientos diferentes según la BAL y el ácido utilizado. $L n$. mesenteroides no fue capaz de mantener el gradiente de $\mathrm{pH}$ en presencia de acético ni de láctico.
Por el contrario, Lb plantarum mantuvo el gradiente de $\mathrm{pH}$ a pesar del bajo $\mathrm{pH}$ exterior, producido por altas concentraciones de cualquiera de los ácidos. Esto parece explicar, la desaparición de Ln. mesenteroides una vez transcurridas las primeras fases de la fermentación de las AV, cuando el pH comienza a descender, así como la capacidad de $L b$. plantarum para llevar a cabo la fase fundamental de la mayoría de las fermentaciones de vegetales y permanecer en las salmueras hasta la completa utilización de las sustancias fermentables. 
La tolerancia de las BAL al $\mathrm{pH}$ y a la acidez se aprovecha en las diferentes preparaciones de aceitunas para limitar el desarrollo de bacterias Gram-negativas y otros microorganismos productores de alteraciones durante las primeras fases de dichos procesos. La disminución del $\mathrm{pH}$ se suele realizar, en el caso de las verdes, mediante el paso de anhídrido carbónico o la adición a la salmuera inicial de un ácido fuerte, habitualmente clorhídrico. En los demás tipos, el acético es más adecuado, empleándose en concentraciones de alrededor del 0,2\% para conseguir bajar el pH inicial a valores de 4,3-4,2.

\section{C) Disponibilidad de azúcares fermentables}

La concentración de azúcares fermentables difiere entre variedades y disminuye a medida que avanza la maduración (Fernández Díez et al., 1985; Garrido Fernández et al., 1997). Asimismo, la cantidad de dichos compuestos en las salmueras depende de los tratamientos a los que se someten los frutos en cada elaboración. En el caso de las AV, las soluciones alcalinas y los lavados eliminan una proporción considerable de los mismos; pero el aumento de permeabilidad que ello provoca en la piel y en la pulpa hace que el nivel de materia fermentable ( $y$ otros nutrientes) disponible desde un principio sea relativamente alto $(0,5-2,0 \%)$, a no ser que el número de lavados o sus duraciones hayan sido excesivos. A causa de estas últimas circunstancias, era relativamente frecuente en la industria californiana la necesidad de incorporar azúcares a las salmueras iniciales (Vaughn et al., 1943). En España, las cantidades perdidas pueden cuantificarse entre el 1 y $2 \%$, dependiendo de las variedades y condiciones de los tratamientos (Fernández Díez et al., 1985); pero, aun así, no se requiere normalmente añadirlos. (Balatsouras (1964) ha encontrado, igualmente, que la variedad griega Conservolia es deficiente en dichas sustancias, lo que ha creado problemas a los elaboradores de este país para su preparación como AV. Sin embargo, este mismo autor ha demostrado que, si a las salmueras se les añade azúcares y se emplea un cultivo iniciador, se consigue una fermentación láctica completa y se alcanzan unas características finales normales (Balatsouras et al., 1983).

El contenido de azúcares reductores en las variedades italianas es, igualmente, diverso; las concentraciones de los mismos en Nocellara etnea y San Agostino fueron sólo del 1,48 y 2,23\%, respectivamente. La preparación en verdes, las deja sin materia fermentable suficiente para que se alcancen valores correctos de $\mathrm{pH}$ y acidez. Sciancalepore (1984) confirmó, no obstante, que con la mencionada adición de glucosa o sacarosa se resolvían todas las dificultades.

En las TN (y de color cambiante) y ANN el contenido de azúcares disminuye con la madurez y su difusión a la salmuera es lenta, debido al mantenimiento de la estructura de la pulpa y de la piel, aunque el intercambio osmótico se facilita a medida que el fruto madura.

\section{D) Disponibilidad de aminoácidos y vitaminas}

El contenido de proteínas en las aceitunas es relativamente bajo, alcanzando tan sólo una proporción del $1-2 \%$. Sin embargo, se ha demostrado que su calidad es excelente y que incluyen la totalidad de los aminoácidos esenciales para el hombre (Fernández Díez et al., 1985). Esto viene, además, avalado por el hecho de que, en las fermentaciones de aceitunas, la presencia de BAL, una vez eliminados los inhibidores, es muy fácil y de todos es sabido que dichas BAL se caracterizan, precisamente, por sus exigencias nutritivas. Esto queda muy claro en las $\mathrm{AV}$, en las que el crecimiento de dichos microorganismos se observa prácticamente desde la incorporación de la salmuera. En las TP y ANN, colocadas directamente en salmuera, la lentitud de los intercambios osmóticos entre el fruto y la solución que las rodea hace que las disponibilidades deban ser bastante más reducidas, sobre todo en los comienzos. Precisamente, esta circunstancia puede ser una de las causas que contribuyan a dificultar la implantación de las BAL en dichas fermentaciones.

En cualquier caso, después del proceso, y una vez que se sustituye la salmuera de fermentación, la concentración de compuestos proteicos es aún menor. Casaroli et al. (1980) encontraron que cuando las aceitunas de la variedad italiana Coratina ya fermentadas se mantenían durante $\mathbf{3 0}$ días en una salmuera del $10 \%$ y a continuación se envasaban con salmuera nueva, no se alteraban después de un período de seis meses. Ello ocurría, incluso a un $\mathrm{pH}$ de 7,4 y sólo con el $4 \%$ de $\mathrm{NaCl}$ y a pesar de inocularlas con Clostridium botulinum y Staphylococcus aureus. Las cantidades de aminoácidos que contenían dichos frutos eran muy bajas, 0,1-0,5 mg/100 g, lo que, al parecer, era la causa de esa estabilidad.

Ruiz Barba y Jiménez Díaz (1995) estudiaron la presencia de las vitaminas esenciales del grupo B en las salmueras de las aceitunas verdes. De sus resultados puede concluirse que los ácidos nicotínico y pantoténico, así como biotina y vitamina $B_{6}$ se encuentran en dichas soluciones desde el principio del proceso. Las concentraciones encontradas fueron muy superiores a las requeridas por $L b$. plantarum para su crecimiento óptimo. Asimismo, se descubrió que varias de las levaduras habitualmente presentes en dichas fermentaciones excretaban cantidades importantes de estos compuestos. En concreto: Pichia membranaefaciens producía todas las vitaminas anteriormente mencionadas; Pichia farinosa, Lodderomyces elongisporus y Candida parasilopsis, formaban los ácidos nicotínico y pantoténico; Candida diddensii, los ácidos anteriores y la vitamina $\mathrm{B}_{6}$; Saccharomyces cerevisiae, vitamina $\mathrm{B}_{6}$; y Pichia salictaria, biotina y ácido pantoténico. Todo ello indica que, aún cuando no parecen absolutamente imprescindibles, las levaduras que siempre acompañan a las bacterias lácticas en las fermentaciones de estos productos o, al menos, algunas 
de ellas, pueden jugar un papel considerable a la hora de favorecer el desarrollo de $L b$. plantarum en las AV.

La disponibilidad de vitaminas cuando los frutos se colocan directamente en salmuera ha de ser indudablemente más baja, por los ya comentados problemas de difusión. En estos casos, puede, por tanto, ser incluso más trascendental la presencia de las levaduras, ya que la dependencia de las BAL con respecto a las vitaminas producidas por las mismas puede ser decisiva.

De cualquier forma, también se ha encontrado que existe una gran capacidad de adaptación de las BAL a las condiciones del medio, con objeto de lograr su supervivencia. Así, se ha encontrado que hay cepas de $L b$. plantarum aisladas de salmueras de aceitunas verdes que no requieren vitamina $B_{6}$, y los ácidos nicotínico y p-aminobenzoico para su crecimiento normal (Ruiz Barba y Jiménez Díaz, 1994). Estas características pueden ser las responsables del mayor vigor con que las cepas salvajes de BAL colonizan muchas de estas salmueras y son capaces de sobrevivir durante períodos de tiempo más prolongados que aquellas provenientes de cultivos iniciadores. Posiblemente éstas, aclimatadas a un medio más favorable, no han desarrollado esas capacidades en la misma extensión y tienen mayores dificultades. Algunos fabricantes de inóculos han asumido dicha hipótesis e incorporan un complemento nutritivo (elementos minerales, aminoácidos, vitaminas, etc.) a los mismos, con el fin de asegurarse que la probable deficiencia de nutrientes en sentido amplio no represente ningún inconveniente para la implantación y multiplicación del microorganismo (Roig y Hernández, 1991).

\section{CARACTERÍSTICAS DEL DESARROLLO DE LAS BACTERIAS LÁCTICAS EN LAS PRINCIPALES ELABORACIONES}

\subsection{Aceitunas verdes}

Han sido las únicas que tradicionalmente han seguido una típica fermentación láctica. Las especiales características climatológicas de los alrededores de Sevilla y de las variedades que se dan en dicha zona fueron factores determinante para el desarrollo de este proceso. Por sus exquisitas cualidades organolépticas han llegado a alcanzar un reconocido prestigio internacional, hasta el punto de denominárselos mundialmente como estilo sevillano o español.

La fermentación en los clásicos «bocoyes» de madera perduró hasta los años setenta. A partir de entonces, el empleo de los depósitos de fibra de vidrio y poliéster, con capacidades para unos $10.000 \mathrm{~kg}$ de frutos (la fermentación en grandes masas), fueron implantándose paulatinamente e hicieron posible la universalización de esta forma de preparación (Borbolla y Alcalá et al., 1969). De cualquier manera, la ela- boración, básicamente, sigue siendo la misma, incluso desde el punto de vista microbiológico, y las BAL continúan jugando un papel esencial en ella.

El proceso fermentativo espontáneo es bastante complejo. Se reconocen actualmente en él cuatro fases. La primera, con una duración entre 5 y 15 días, se distingue por el crecimiento de bacterias Gramnegativas y cocos lácticos. La actividad de todos estos gérmenes hace descender el $\mathrm{pH}$ con cierta rapidez en este período. La segunda, entre 10 y 15 días, se inicia cuando aparecen los primeros lactobacilos, cuya población va progresivamente creciendo a medida que pasa el tiempo. Termina con la desaparición de las bacterias Gram-negativas. En el transcurso de la tercera fase, la población de lactobacilos es absolutamente dominante. Durante ella ocurren las transformaciones físico-químicas y organolépticas más acusadas y el producto adquiere sus cualidades distintivas típicas. Finaliza cuando se han consumido los azúcares fermentables. La cuarta fase abarca todo el período de conservación de los frutos fermentados. En el curso de la misma, se produce un aumento de la acidez volátil y una cierta elevación del pH. Si las modificaciones son ligeras, su influencia en la estabilidad de las aceitunas no es apreciable. En cambio, si el ascenso del $\mathrm{pH}$ es superior a 0,4 unidades, puede propiciarse la aparición de algunas alteraciones indeseables, principalmente la «zapatería». Por tanto, esta cuarta fase, debida al crecimiento de especies de Propionibacterium, no es deseable y debe evitarse, lo que se consigue mediante la adecuada subida de la concentración de sal. Una descripción más completa de los diferentes aspectos de esta fermentación se puede encontrar en González Cancho (1963), Borbolla y Alcalá y Rejano Navarro (1979), Vaughn (1982), Fernández Díez et al. (1985) y Garrido Fernández et al. (1997).

En general, la producción de ácido en este proceso se debe a los diferentes gérmenes ácido lácticos. Las especies de cocos encontradas, principalmente en el transcurso de la primera y segunda fase, son: Streptococcus (Lactococcus) lactis y Pediococcus urinae-equi, de metabolismo homofermentativo y Leuconostoc paramesenteriodes, heterofermentativo. Este último es el que ha presentado siempre un intervalo de permanencia mayor (González Cancho y Durán Quintana, 1981). Dadas sus características, la contribución de los mismos a la acidez final debe ser limitada.

Por otra parte, en estas fermentaciones se han descrito diferentes especies de lactobacilos. Vaughn (1943, 1982) encontró Lb. plantarum en la mayoría de los casos, así como Lactobacillus brevis. Este sólo se daba en salmueras de aceitunas de la variedad Gordal, en la cual se utilizaban concentraciones iniciales de sal relativamente bajas. González Cancho (1963) ha señalado la presencia de $L b$. plantarum y Lactobacillus delbrueckii, aunque este último en una proporción mucho más baja. Rodríguez Quiñones et al. (1983) identificaron las siguientes especies (además de $L$ b. plantarum que era el predominante): Lactobaci- 
Ilus casei, Lactobacillus fermentum, Lactobacillus cellobiosus, Lactobacillus coryniformis y Lb. brevis, en orden decreciente de importancia. Asimismo, Van den Berg et al. (1993) han identificado Lactobacillus paracasei en aceitunas verdes portuguesas, aunque sin dar detalles de las condiciones de fermentación. Balloni et al. (1973), en una revisión de salmueras de aceitunas verdes de las variedades italianas Ascolana, Nocellara, Ottobrarica y Cerignola, encontraron $L b$. plantarum (en todas ellas), Lb. brevis (en tres de ellas, con frecuencias de 10-50\%), Lb. fermentum (en dos, $10-30 \%$ ), Lb casei var. rhamnosus (una, 10\%) y $L b$ casei var. alactosus (una, 10\%). Por todo ello, se puede concluir que la especie característica de este tipo de fermentación es $L b$. plantarum, haciendo notar que una proporción importante de las cepas de lactobacilos encuadrados dentro de esa especie habrían sido identificadas en la actualidad como Lactobacillus pentosus.

Mientras los frutos están en salmuera es también normal la presencia de una población moderada de levaduras, que ha sido estudiada por González Cancho en diversas ocasiones (1960, 1963 y 1965). El desarrollo de las mismas, como ya se ha comentado antes, puede tener un efecto de sinergía para el crecimiento de los lactobacilos y no se considera contraproducente, a no ser que lleguen a predominar claramente sobre las BAL.

La población del BAL puede verse afectada, además de por los factores condicionantes de tipo general expuestos anteriormente, por otros más específicos del proceso de preparación de las AV. Entre ellos pueden mencionarse:

\section{A) Modificaciones en los tratamientos alcalinos y lavados}

En los últimos años, estas operaciones están sufriendo una serie de cambios con el objeto de disminuir la contaminación y el volumen de vertidos generados. En este sentido, es cada vez más frecuente la re-utilización de las lejías de «cocido» y la reducción del número de lavados (Fernández Díez et al. 1985; Garrido Fernández et al., 1977). Ello trae consigo que las salmueras retengan habitualmente una «lejía residual», o acidez combinada, algo más alta de lo que era tradicional. Es, entonces, normal que la actividad de los lactobacilos se pueda prolongar durante períodos más amplios y se produzcan niveles elevados de acidez, aunque con valores de $\mathrm{pH}$ algo superiores. Este efecto puede acentuarse cuando se trabaja con concentraciones altas de $\mathrm{NaOH}$ en las lejías, se disminuye de forma sensible el número de lavados o se acorta la duración de los mismos. Esto último aumenta la cantidad de materia fermentable disponible, la formación de la acidez correspondiente y, por supuesto, la acidez combinada.
Sin embargo, este exceso de «lejía residual», puede dificultar la obtención de los relativamente bajos valores de $\mathrm{pH}$ requeridos en el envasado final. El problema se evita, a veces, corrigiendo aquella mediante la adición a la salmuera inicial de una cierta proporción de un ácido fuerte. Se ha comprobado que esta práctica puede tener repercusiones negativas en el crecimiento de las BAL, dando lugar en numerosas ocasiones a fermentaciones detenidas (González Cancho et al., 1983). Esto puede deberse, por un lado, a la propia bajada drástica del $\mathrm{pH}$ y a la limitada tolerancia a dicho efecto de muchas de las BAL comunes en las aceitunas verdes $y$, por otro, a la menor disponibilidad de nutrientes en el medio, provocada por la precipitación de aminoácidos y proteínas que ocasiona también el ácido. Afortunadamente, se ha encontrado que cuando se efectúa la adición en dos fases, la primera en la solución salina inicial y la segunda una vez que ha acabado la fermentación, dichos inconvenientes se solucionan (González Cancho et al., 1984; Rejano et al., 1986). En caso de realizar inoculaciones, la adición de ácido puede resultar contraproducente si no se espera el tiempo suficiente para que el valor de $\mathrm{pH}$ vuelva a subir, al menos parcialmente, antes de la incorporación de las bacterias.

\section{B) Tratamientos con calor y facilidad de fermentación}

Etchells et al. (1966) hallaron que dando un tratamiento previo con calor a los frutos $\left(3 \min\right.$ a $\left.74^{\circ} \mathrm{C}\right)$ se mejoraba la rapidez de su fermentación posterior como AV, mientras que congelándolas se producía el efecto contrario (Fleming y Etchells, 1967; Juven y Henis, 1970). La acción favorable se atribuyó a la destrucción térmica del inhibidor de las aceitunas así como al aumento de la permeabilidad de las membranas celulares del fruto (Juven y Henis, 1970).

Igualmente, Juven et al. (1968a) informaron que las aceitunas tratadas con una solución caliente de hidróxido sódico fermentaban mejor, alcanzaban una mayor acidez en ácido láctico y presentaban un color y características organolépticas más adecuadas que aquellas que se habían sometido a idéntico proceso a temperatura ambiente. También Sciancalepore (1984) obtuvo resultados muy ventajosos utilizando una técnica parecida en la preparación de aceitunas verdes de las variedades Nocellara etnea y San Agostino. Es más, cuando el control de la temperatura se combinó con una concentración baja en la «lejía» se pudo conseguir una fermentación normal, incluyendo la acidez combinada, y una gran reducción en la contaminación, al poderse eliminar las aguas de lavado (Sánchez Gómez et al., 1990). Este sistema tiene el inconveniente, por el contrario, de que un ligero exceso en la temperatura o en la concentración de álcali puede causar deterioros irrecuperables en la textura de los frutos, tal como señalan los mismos autores antes 
mencionados. Por tanto, la aplicación de dichas modificaciones sólo tendrá sentido cuando se utilice como una medida descontaminante, ya que, como ya demostraron suficientemente Borbolla y Alcalá et al. (1969), el tratamiento alcalino a temperatura ambiente, cuando se aplica bien, es suficiente para conseguir un buen proceso fermentativo. A la misma conclusión llegaron Balatsouras et al (1983), quienes confirmaron estos resultados en la preparación de aceitunas verdes de la variedad Conservolia al encontrar que, en este caso, era más importante la incorporación de materia fermentable y el empleo de inóculo que la aplicación de calor.

Sin embargo, recientemente Sánchez et al. (1995) han encontrado que, cuando se emplea agua caliente (aproximadamente unos $40^{\circ} \mathrm{C}$ ) en la etapa de los lavados, el posterior proceso láctico se acelera. La razón de ello no está aún totalmente esclarecida, pero es una práctica que podría aplicarse sin los riesgos para la textura que conlleva trabajar con las soluciones de hidróxido sódico a temperatura controlada (superior a la ambiente). La utilización de cultivos iniciadores podría completar la efectividad de dicha medida y favorecer una fermentación más rápida.

\subsection{Aceitunas tipo negras (y de color cambiente)}

El contenido de azúcares y polifenoles, con excepción de las antocianinas, disminuye en el transcurso de la maduración de las aceitunas. Asimismo, desde el comienzo de la aparición de las primeras tonalidades rosadas, se produce un progresivo aumento de la permeabilidad de la piel y de la concentración de sustancias hidrosolubles en la pulpa. Todo ello condiciona de manera destacada la evolución de la fermentación en los frutos colocados directamente en salmuera, facilitando el crecimiento de BAL a medida que los mismos son más maduros. Así, al trabajar con aceitunas verdes de la variedad Hojiblanca difícilmente se llega a conseguir el desarrollo de BAL; pero, cuando se encuentran en el momento de color cambiante, ya suelen aparecer esporádicamente. Finalmente, si se cogen en estado de completa madurez, la presencia de BAL es normal, siempre que las concentraciones de sal no sean tan altas como para inhibirlas.

Así, en general, el proceso fermentativo de aceitunas verdes y de color cambiante en salmuera se debe a la actividad de levaduras (Fernández Díez et al, 1985; Garrido Fernández et al. 1997; González Cancho et al., 1975; Balatsouras, 1966). En tales casos la presencia de BAL es ocasional, dependiendo de las variedades y de las concentraciones de sal.

Debido a que en estos frutos no existe la esterilización superficial que se produce en la práctica durante el tratamiento con lejía, la carga microbiana inicial que traen las aceitunas del campo puede condicionar los microorganismos que se desarrollen posteriormen- te en las salmueras. Balloni (1973) ha estudiado la flora epifítica de diferentes variedades italianas procedentes de diversas regiones, encontrando que estaba compuesta fundamentalmente por $L b$. plantarum, $L b$. brevis, and $L b$. fermentum. La fermentación de dichas aceitunas mostró que, efectivamente, los gérmenes que portaban habían colonizado las salmueras correspondientes, con independencia de que el proceso se efectuara a escala industrial o artesanal. Cuando predominaron las BAL se obtuvo un producto de excelente calidad. En cambio, si las levaduras superaban a las BAL se apreciaba un cierto deterioro en el mismo. Estudios posteriores realizados por Pelagatti (197880 ) indicaron que las especies $L b$. plantarum y $L b$. brevis estaban en las superficies de todas las variedades, mientras que $L b$. fermentum, $L b$. delbrueckii y $L b$. coryniformis subsp. coryformis se encontraron sólo en cuatro; otras especies sólo se aislaron de una variedad. En todos los casos se confirmó el paso de todas ellas a las soluciones en las que se colocaron.

La variedad española Gordal tiene una gran facilidad para permitir el desarrollo de lactobacilos cuando se coloca directamente en salmuera inicial del $7 \%$ en $\mathrm{NaCl}$, a la que se le añadía el $1 \%$ de sal cada quince días, se produjo una fermentación de características muy similares a cuando se prepara al estilo sevillano. La figura 3 muestra el crecimiento de $\mathrm{Lb}$. plantarum en el transcurso de la fermentación de esta variedad entre tres condiciones diferentes de fermentación, siendo de resaltar que no se produjeron diferencias entre recipientes inoculados o no. Asimismo, en la figura 4 se recoge la población de Pediococcus sp en el mismo caso anterior. Su persistencia es similar a la de los lactobacilos y, en determinados momentos, superior a la de estos. Cuando la concentración de sal se elevó por encima del $8 \%$, se detuvo la formación de ácido y el producto se estabilizó (Durán Quintana et al., 1991). Un caso parecido se ha descrito con la variedad Aloreña, estando, en este caso, la población láctica formada por $L b$. plantarum y Pediococcus sp. La tendencia a la fermentación láctica de esta variedad es tan acusada que la misma se produce incluso en condiciones físico-químicas de equilibrio extremas tales como colocación en salmueras del $9 \%$ de $\mathrm{NaCl}$ con corrección con acético $(0,2 \%)$ o altas concentraciones de ácido $(0,6 \%)$ y moderadas de sal $(6 \%)$. Indudablemente, el empleo de condiciones más suaves $(6 \% \mathrm{NaCl}$ y $0,2 \%$ acético) y el uso de inóculo da lugar a un claro proceso fermentativo láctico. En todos los supuestos se subió la sal un $1 \%$ quincenal, la cantidad de ácido láctico formada fue considerable y el $\mathrm{pH}$ descendió lo suficiente como para asegurar la estabilidad del producto hasta su uso como aceitunas «aliñadas». Un detalle interesante a resaltar en dicha fermentación es que la secuencia de aparición de Pediococcus sp y Lb. plantarum se altera completamente. La población de Pediococcus sp alcanzó niveles moderadamente elevados, perduró durante todo el tiempo de conservación e, incluso, llegó a superar a la de $L b$. plantarum en las últimas etapas del mismo (García García et al., 1992). 


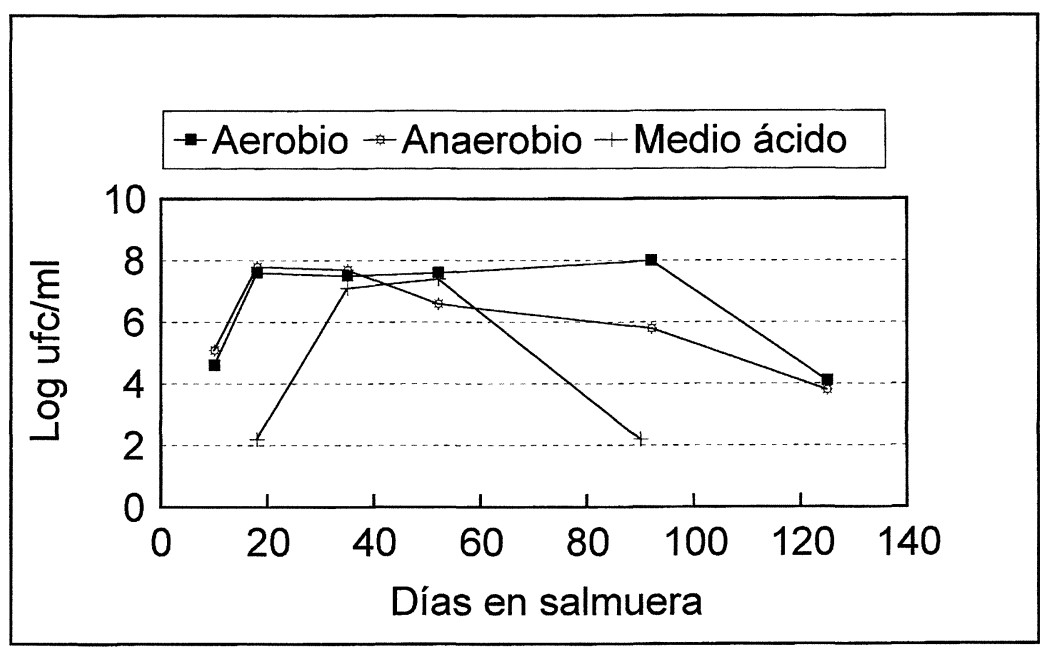

Figura 3

Evolución de la población de Lactobacillus plantarum en la fermentación de aceitunas de la variedad Gordal colocadas directamente en salmuera. Concentración inicial de sal, $6 \%$ y corrección del pH con el $0,3 \%$ de acético. En el medio ácido el porcentaje de acético fue el 1,5\% y la sal el 6 y $3 \%$. Tomado de Durán Quintana et al. (1991)

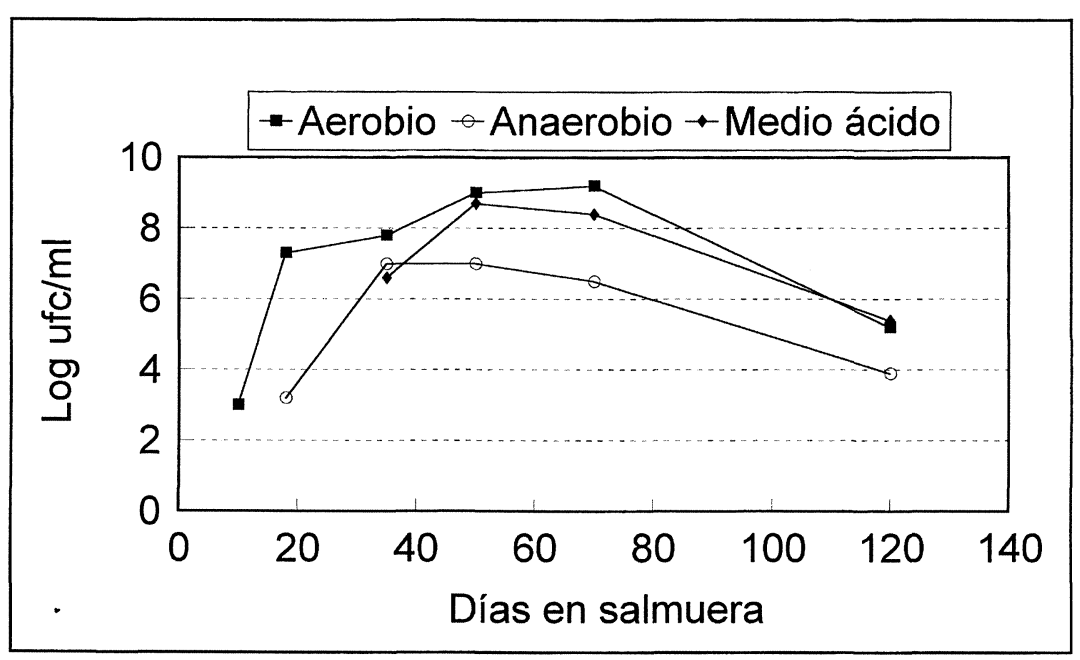

Figura 4

Evolución de la población de Pediococcus sp en la fermentación de aceitunas de la variedad Gordal colocadas directamente en salmuera. Concentración inicial de sal, $6 \%$ y corrección del pH con el $0,3 \%$ de acético. En el medio ácido el porcentaje de acético fue el 1,5\% y la sal el 6 y $3 \%$. Tomado de Durán Quintana et al.

(1991). 
En cambio, otras variedades tienen, con el mismo estado de madurez, un comportamiento completamente diferente. Así, en Hojiblanca únicamente se observó la presencia de lactobacilos cuando se colocó en agua (Fernández González et al., 1993); concentraciones del $3 \%$ de sal y superiores ya resultaron inhibidoras (Fernández González et al. 1992). Un comportamiento similar parece seguir la Manzanilla, en la que sólo se observó crecimiento de BAL en aquellos casos de concentraciones muy bajas de sal, tanto en presencia como en ausencia de aire (Garrido Fernández et al., 1986). Asimismo, la variedad Arbequina se caracteriza por ofrecer una gran resistencia a la colonización de sus salmueras por BAL, aún en presencia de niveles muy bajos de $\mathrm{NaCl}$, calentamiento de los frutos ( $3 \mathrm{~min} . \mathrm{A} 74^{\circ} \mathrm{C}$ ) o la ayuda de un inóculo (Torre et al., 1993). Este comportamiento se debe al alto contenido en polifenoles de todas ellas cuando se recogen en este estado de madurez. La utilización de cultivos iniciadores puede ser interesante para mejorar el crecimiento de las BAL en las aceitunas de color cambiante o verdes destinadas a la preparación del tipo negras.

\subsection{Aceitunas negras naturales}

Los principales polifenoles de las aceitunas negras naturales son las antocianinas, que son los compuestos responsables de la coloración rosada a púrpura que va apareciendo en las mismas. Su contenido aumenta a medida que avanza la maduración (Maestro Durán et al., 1976; Vhalov, 1990), al igual que las sustancias hidrosolubles. Por el contrario, en este período disminuye el contenido en oleuropeína, por lo que los frutos van siendo cada vez menos amargos. Sin embargo, para preparar este tipo no puede esperarse a la completa madurez, ya que en ese momento la textura sería excesivamente deficiente. Es necesario llegar a un compromiso entre ambos atributos, por lo que, en el momento de la recolección, la materia prima suele conservar aún un sabor amargo bastante resaltado y la madurez llegar sólo a la mitad de la pulpa. En los procesos tradicionales en salmuera, lo normal era que el proceso durara hasta después del verano, para dar lugar al suficiente endulzamiento en el producto final.

Al igual que ocurría en las de color cambiante, la capacidad tampón de estas salmueras es muy reducida al no existir tratamiento alcalino. Por ello, la producción de ácido suele conducir a una rápida disminución de los valores de pH. Esto, a su vez, lleva a una decoloración de las aceitunas, porque el color púrpura de las antocianinas vira a rojo intenso a medida que el $\mathrm{pH}$ desciende. En los sistemas de elaboración clásicos, este efecto no era conveniente, por lo que nunca se procuró la consecución de procesos lácticos. De hecho, la acidez obtenida en las industrias griegas del ramo oscilaba entre $0,1 \%$ a $0,4 \%$ (Balatsouras, 1966).
Estos valores, y sus correspondientes de $\mathrm{pH}$, no eran suficientes para garantizar la estabilidad del producto, por lo que, tradicionalmente, ha sido necesario el uso de altas concentraciones de sal.

Por ello, en los procesos clásicos de preparación de ANN, la presencia de las BAL ha sido más bien rara. Sin embargo, el mismo Balatsouras (1966) reconoce que en algunos casos de sal más baja la materia fermentable se convertía fácilmente en ácidos.

De acuerdo con la experiencia española, el desarrollo de BAL en las salmueras de ANN depende de la variedad. En caso de emplearse Hojiblanca, el crecimiento de lactobacilos ha sido detectado incluso a concentraciones tan altas de sal en el equilibrio como el $8 \%$. En cambio, en Lechín, Nevadillo blanco, Nevadillo negro y Verdial nunca se han encontrado BAL (Durán Quintana et al., 1971 y 1973; Garrido Fernández et al., 1973; Durán Quintana y González Cancho, 1973). Entre los factores condicionantes de estas fermentaciones, González Cancho et al. (1975), menciona, en el proceso anaerobio tradicional, los siguientes: contenido de polifenoles en las salmueras, concentración de sal, disponibilidad de materia fermentable y temperatura. Algunos de ellos ya se han comentado en sus aspectos generales, por lo que sólo se resaltarán aquí los detalles específicos relacionados con las ANN. Aparentemente, la Hojiblanca madura no tiene la cantidad suficiente de polifenoles para detener el crecimiento de las BAL. Existe una concentración importante de antocianinas; pero, hasta ahora, no se ha descrito efecto negativo alguno de las mismas sobre dichos microorganismos. Por otra parte, la concentración de azúcares libres en estos frutos suele ser baja, aunque suficiente para dar valores de acidez superiores al $1 \%$. No obstante, este sustrato va pasando a la solución poco a poco, por lo que raras veces se consiguen concentraciones elevadas. Esto constituye un serio inconveniente para la implantación de la población láctica, que, en muchas ocasiones, tiene que competir en condiciones desfavorables con las levaduras, que no están sujetas al efecto inhibidor de los polifenoles. Existe también una cantidad importante de otras materias fermentables en estos frutos, que proviene del resto de las sustancias hidrosolubles. En estos casos, los azúcares están combinados y su disponibilidad depende de la hidrólisis química de estos compuestos o de la acción de determinadas enzimas específicas. En el segundo supuesto, las levaduras parecen estar mejor capacitadas para su aprovechamiento.

Estos procesos se aplican habitualmente con concentraciones del 8 al $10 \%$ de sal en el equilibrio, las cuales, de por sí, impiden el crecimiento de la práctica totalidad de las BAL. Para permitir su desarrollo es necesario recurrir a valores más bajos, a pesar de que, de acuerdo con Balatsouras (1985), las BAL aisladas de las salmueras de ANN son bastante más resistentes a la sal que aquellas provenientes de $A V$ (figura 1). 
Finalmente, estas fermentaciones suelen iniciarse en épocas del año en que las temperaturas son relativamente bajas, $12-18^{\circ} \mathrm{C}$, lo que tampoco favorece la implantación de las BAL. Sin embargo, no es conveniente aplicar calor, ya que cuando la misma se eleva por encima de los $20^{\circ} \mathrm{C}$, la experiencia en variedades españolas es que se incrementa proporcionalmente mucho más la población de levaduras y, en la mayoría de los casos, ello lleva a la aparición de alteraciones relacionada con la textura, principalmente a la formación de alambrado y «afarolado».

Recientemente se están comenzando a estudiar con detalle las características de los procesos de preparación de estas aceitunas utilizados en Turquía. Borcakli et al. (1993) ha informado de los resultados de la fermentación de las dos principales variedades de este país, Edençik y Gemlik, que se lleva a cabo con concentraciones de $\mathrm{NaCl}$ entre el 10 y $13 \%$. Con estos niveles de sal, la presencia de BAL no es posible. Como microorganismos productores de láctico únicamente encontraron Pediococcus sp en el período comprendido entre los días 76 y 86 de la colocación en salmuera. En otras investigaciones (Özay y Borcakli, 1996) han ensayado condiciones más adecuadas para el crecimiento de las BAL, tales como el mantenimiento de las aceitunas en agua durante los primeros 24 días (la cual se cambia entonces por salmueras del 6 y $14 \%$ ) y concentraciones de sal del $6 \%$ a lo largo de todo el período. El comportamiento observado fue muy diferente con respecto al clásico. En el caso de usar agua al principio, la población de BAL subió, progresivamente, hasta alcanzar valores de $10^{5}$ unidades formadoras de colonias por $\mathrm{ml}$ (ufc/ml). Dicho desarrollo se detuvo cuando la solución se sustituyó por una salmuera al $14 \%$ y continuó en el caso del $6 \%$ de sal, aunque con unos recuentos más moderados $\left(10^{3}\right.$ $\mathrm{ufc} / \mathrm{ml}$ ). Las especies encontradas fueron Lc. mesenteroides, que predominó durante los primeros días de la colocación en salmuera, y Lb. plantarum a partir del cambio de salmuera. En el supuesto de utilizar una salmuera baja (6\%) desde el principio, se identificó únicamente $L b$. plantarum. Sin embargo, el crecimiento debió ser relativamente limitado ya que el $\mathrm{pH}$ final se mantuvo en torno a 4,5 unidades, lo que no fue suficiente para asegurar la conservación del producto (que se consiguió aumentando la concentración de sal). Los frutos presentaban unas características similares a las del proceso tradicional, especialmente en cuanto al color. Parece, pues, que las variedades turcas son también susceptibles de soportar el crecimiento de las BAL cuando se dan las condiciones físico-químicas adecuadas.

Los primeros en diseñar un proceso láctico típico para las aceitunas negras naturales fueron Balatsouras y Polymenacos (1964), aunque con características similares al de $\mathrm{AV}$, al implicar un tratamiento con álcali previo a la colocación en salmuera y bajar la concentración de sal al 6-7\%. De esta forma, se obtuvo un desarrollo de lactobacilos muy abundante, una acidez libre del 0,8 al $1 \%$ y unos valores de $\mathrm{pH}$ comprendidos en el intervalo $3,65-3,80$, condiciones muy apropiadas para la conservación del producto. En realidad se conseguía un perfecto proceso estilo sevillano con aceitunas negras maduras. Las características del producto final diferían considerablemente de las tradicionales. El sabor era ácido y agrio y, sobre todo, el color era completamente diferente, al presentar los frutos unas tonalidades rojizas intensas a las que los consumidores no estaban acostumbrados. Esta iniciativa no ha sido nunca secundada por la industria.

A partir de los años ochenta, en España se desarrolló un nuevo sistema de elaboración para las ANN y para el período de conservación de las TN. El mismo implica el mantenimiento de un cierto nivel de oxígeno disuelto durante la etapa activa de fermentación principalmente. Ha sido estudiado con detalle por los investigadores del Instituto de la Grasa. El empleo de un medio aerobio no ha representado ningún inconveniente para el crecimiento de las BAL en las mismas condiciones en las que también lo hacían en medio anaerobio. Así, la variedad Hojiblanca preparada por este sistema presenta crecimiento de $L b$. plantarum a partir del día 20 de la colocación en salmuera y su población alcanza el máximo hacia los 60 días (García García et al., 1982). La adición simultánea de cloruro cálcico ( $2 \%$ ) a estas soluciones, con objeto de mejorar la textura, ha tenido un efecto desfavorable sobre el crecimiento de las BAL, posiblemente debido a la suma de las acciones de los iones $\mathrm{Ca}^{++}$y $\mathrm{Na}^{+}$(Durán Quintana et al., 1986). En algunos casos, se ha sugerido la utilización con este sistema de concentraciones iniciales de sal bastante bajas $(2 \% \mathrm{NaCl})$, lo que, junto con la inyección de aire, ha repercutido favorablemente en el desarrollo de las BAL. La población ha estado constituida por microorganismos de los géneros Pediococcus y Leuconostoc sp., que han permanecido hasta los 20 días, y Lb. plantarum, que estuvieron viables hasta los 60 días. Esta última inhibición es lógica, puesto que para ese momento la concentración de $\mathrm{NaCl}$ había alcanzado ya unos niveles del $9 \%$. De cualquier forma, la intensidad del proceso fue suficiente para que el $\mathrm{pH}$ descendiera hasta 3,6-3,8 unidades, lo que aseguró unas buenas condiciones para la estabilización del producto (Garrido Fernández et al., 1987).

La posible utilización de cultivos iniciadores en estos procesos fermentativos, cuyo crecimiento se puede controlar perfectamente mediante la concentración de sal, puede ser conveniente para obtener una fermentación láctica parcial. Con ello se consigue un buen equilibrio entre características físico-químicas, textura y color, lo que llevaría la obtención de productos finales de mejor calidad, una mayor seguridad para el fabricante y un menor riesgo para el consumidor. 


\section{CONCLUSION}

Como se ha puesto de manifiesto a lo largo de esta revisión, las bacterias lácticas tienen un papel esencial en la elaboración de las aceitunas verdes estilo español o sevillano, son convenientes en el caso de las etapas de conservación de las aceitunas tipo negras y, adecuadamente controladas, pueden también contribuir a obtener productos más seguros de negras naturales. En las condiciones actuales de fabricación, todos estos procesos fermentativos, no obstante, siguen siendo espontáneos. Aún así, el empleo de cultivos iniciadores en los que las BAL estén presentes puede ser aconsejable. Es más, en un futuro, el empleo de los mismos va a ser imprescindible en el momento en que los actuales fermentadores tengan que modificarse para mejorar las condiciones higiénicas de trabajo. Es un cambio que el Sector debe plantearse a medio y largo plazo.

\section{AGRADECIMIENTO}

A la CICYT por la ayuda concedida dentro del Proyecto ALI94-0980-C02-01, dentro de cuyas actividades se encuadra este trabajo.

\section{BIBLIOGRAFÍA}

Anónimo (1994). - «Situación y evolución del mercado internacional de las aceitunas de mesa»-. Olivae 54, 1821.

Balatsouras, G. D. (1964). -«Composition chimique des olives noires de Greece. Variations de quelques conditionant en function de la région de production»-. Inf. Oleic. Int. 28, 131-156.

Balatsouras, G. D. (1966). - «The chemical composition of the brine of stored greek black olives»-. Grasas y Aceites 17, 83-88.

Balatsouras, G. D. (1985). - -Taxonomic and physiological characteristics of the facultative rod type lactic acid bacteria isolated from fermenting green and black olives".- Grasas y Aceites 36, 239-249.

Balatsouras, G. D. y Polymenacos, N. G. (1964). -«Resultats preliminaires sur la fermentation des olives noires par acide lactique"-. Informations Oleicoles Internationales 27, 153-167.

Balatsouras, G. D., Tisibri, A., Dalles, T. y Doutsias, G. (1983). - «Effects of fermentation and its control on the sensory characteristics of Conservolea variety green olives"-. Appl. Environ. Microbiol. 46, 68-74.

Balloni, W., Brighigna, A., Cucurachi, A. y Florenzano, G. (1973). - «Prime ricerche sulla microflora lattica di alcune varietà italiane di olive da tavola e delle relative salamoie»-. Ann. Ist. Sper. Elaiot. III, 107-141.

Bobillo, M. y Marshall, V. M. (1991). - «Effect of salt and culture aeration on lactate and acetate production by Lactobacillus plantarum»-. Food Microbiology 8, 153160.
Bobillo, M. y Marshall, V. M. (1992). - «Effect of acidic pH and salt on acid end products by Lactobacillus plantarum in aereted glucose-limited continous culture»-. J. Appl. Bacteriol. 73, 67-70.

Borbolla y Alcalá, J. M. R. de la y Rejano Navarro, L. (1979). - «Sobre la preparación de aceitunas estilo sevillano. La fermentación. l»-. Grasas y Aceites 30, 175-185.

Borbolla y Alcalá, J. M. R. de la, Fernández Díez, M. J. y González Cancho, F. (1969). - «Influence of pasteurization and lye treatment on the fermentation of Spanish-style Manzanilla olives»-. Appl. Microbiol. 17, 734-736.

Borbolla y Alcalá, J. M. R. de la, Fernández Díez, M. J., González Cancho, F. y Cordón Casanueva, J. L (1969). - «studios sobre el aderezo de aceitunas verdes XXIII. La preparación y fermentación de las aceitunas en recipientes de gran capacidad»-. Grasas y Aceites 20, 55-56.

Borcakli, M., Ozay, G., Alperden, I., Ozsan, E. y Erdek, Y. (1993). - "Changes in chemical and microbiological composition of two varieties of olive during fermentation»-. Grasas y Aceites 44, 253-258.

Casaroli, A., Trabucchi, G. y Gola, S. (1980). - Fermentazione e stabilita della olive in salamoia»Industria Conserve 55, 23-30.

Ciafardini, G., Marsilio, V., Lanza, B. y Pozzi, N. (1994). - «ydrolysis of oleuropein by Lactobacillus plantarum strains associated with olive fermentation"-. Appl. Environ. Microbiol. 60, 4142-4147.

COI(Consejo Oleícola Internacional), 1981. - «Norma cualitativa aplicable a las Aceitunas de Mesa en el comercio Internacional»-. Madrid.

Durán Quintana, M. C., y González Cancho, F. (1973). - Estudio microbiológico de la fermentación de aceitunas negras maduras en salmuera. |»-. Microbiología Española 26, 149-164.

Durán Quintana, M. C., Brenes Balbuena, M., García García, P., Fernández González, M. J. y Garrido Fernández, A. (1991). - «Aceitunas tipo negras. Estudio comparativo de tres procedimientos para la conservación previa de frutos de la variedad gordal (O. europae regalis)»-. Grasas y Aceites 42, 106-113.

Durán Quintana, M. C., García García, P. y Garrido Fernández, A. (1986). - «Fermentación en medio aeróbico de aceitunas maduras en salmuera con inyección alternante de aire. Estudio de la influencia de la adición de cloruro cálcico sobre la textura»-. Grasas y Aceites 37, 242-249.

Durán Quintana, M. C., Garrido Fernández, A., González Cancho, F. y Fernández Díez, M. J. (1971). -«Aceitunas negras maduras en salmuera. I. Estudio físico-químico y microbiológico de la fermentación»-. Grasas y Aceites 22, 167-177.

Durán Quintana, M. C., Garrido Fernández, A., González Cancho, F. y Fernández Díez, M. J. (1973). - «Aceitunas negras maduras en salmuera. III. Estudio físico-químico y microbiológico de la fermentación»-. Grasas y Aceites 24, 149-159.

Etchells, J. L., Borg, A. F., Kittel, J. D., Bell, T. A. y Fleming, H. P. (1967). - «Pure culture fermentation of green olives»-. Appl. Microbiol. 14, 1027-1041.

Fernández Díez, M. J., De Castro Ramos, R., Garrido Fernández, A., González Cancho, F., González Pellissó, F., Nosti Vega, M., Heredia Moreno, A., Mínguez Mosquera, M. I., Rejano Navarro, L., Durán Quintana, M. C., Sánchez Roldán, F., García García, P. y Castro de A. (1985). - Biotecnología de las aceitunas de mesa»Consejo Superior de Investigaciones Científicas. Madrid. 
Fernández González, M. J., Garrido Fernández, A., García García, P., Brenes Balbuena, M. y Durán Quintana, M. C. (1992). - «Características del proceso fermentativo durante la conservación de aceitunas de la variedad Hojiblanca, destinadas a la elaboración del tipo negras"-. Grasas y Aceites 43, 212-218.

Fernández González, M. J., García García, P., Garrido Fernández, A. y Durán Quintana, M. C. (1993). - «Microflora of the aerobic preservation of directly brined green olives from Hojiblanca cultivar»-. Appl. Bacteriol. 75, 226-233.

Fleming, H. P. y Etchells, J. L. (1967). - «Ocurrence of an inhibitor of lactic bacteria in green olives»-. Appl. Microbiol. 15, 1178-1184.

Fleming, H. P., Walter, W. M. y Etchells, J. L. (1969). - «Isolation of a bacterial inhibitor from green olives»-. Appl. Microbiol. 18, 856-860.

Fleming, H. P., Walter, W. M., Etchells, J. L. (1973). - «Antimicrobial properties and products of its hydrolysis from green olives»-. Appl. Microbiol. 26, 777-782.

García García, P., Durán Quintana, M. C., Brenes Balbuena, M. y Garrido Fernández, A. (1992). -«Lactic fermentation during the storage of "Aloreña" cultivar untreated green table olives"-. J. Appl. Bacteriol. 73, 324-330.

García García, P., Durán Quintana, M. C. y Garrido Fernández, A. (1982). -«Modificaciones del proceso de fermentación de aceitunas negras al natural para evitar alteraciones»-. Grasas y Aceites 33, 9-17.

Garrido Fernández, A., González Pellisó, F., González Cancho, F., Sánchez Roldán, F., Rejano Navarro, L., Cordón Casanueva, J. L. y Fernández Díez, M. J. (1977). - «Modificaciones de los procesos de elaboración y envasado de aceitunas verdes de mesa en relación con la eliminación y reuso de salmueras»-. Grasas y Aceites 28, 267-285.

Garrido Fernández, A. y Vaughn, R. H. (1978). - «Utilization of oleuropein by microorganisms associated with olive fermentation»-. Can. J. Microbiol. 24, 680-684.

Garrido Fernández, A., Durán Quintana, M. C. y García García, P. (1986). -«Estudio de diferentes formas de conservación de aceitunas de color cambiante de la variedad Manzanilla»-. Grasas y Aceites 37, 1-7.

Garrido Fernández, A., Durán Quintana, M. C. y García García, P. (1987). -«Fermentación en medio aeróbico de aceitunas negras al natural en salmuera. Efecto de algunas variables sobre la formación de "alambrado"»-. Grasas y Aceites 38, 27-32.

Garrido Fernández, A., Durán Quintana, M. C., González Cancho, F. y Fernández Díez, M. J. (1973). -«Aceitunas negras maduras en salmuera. II. Estudio físico-químico y microbiológico de la fermentación»-. Grasas y Aceites 23, 22-31.

Garrido Fernández, A., Fernández Díez, M. J. y Adams, R. M. (1997). - «Table olive. Production and processing»-. Chapman \& Hall. London.

González Cancho, F. (1960). -«Estudios sobre el aderezo de aceitunas verdes. XVII. Levaduras presentes en la fermentación»-. Grasas y Aceites 11, 9-14.

González Cancho, F. (1963). -«Microorganismos que se desarrollan en el aderezo de aceitunas verdes estilo español»-. Microbiología española 16, 221-230.

González Cancho, F. (1965). - «Levaduras en la fermentación de aceitunas verdes estilo español. Estudio cuantitativo»-. Grasas y Aceites 16, 230-234.
González Cancho, F. y Durán Quintana, M. C. (1981). - Bacterias cocáceas del ácido láctico en el aderezo de aceitunas verdes»-. Grasas y Aceites 32, 373-379.

González Cancho, F., Fernández Díez, M. J., Nosti Vega y M., Buzcu, N. (1973). - "Characteristiques des principaux microorganism responsables de la "Zapatería"»-. Informations Oleicoles Internationales 60-61, 133-144.

González Cancho, F., Nosti Vega, M., Durán Quintana, M. C., Garrido Fernández, A. y Fernández Díez, M. J. (1975). - «El proceso de fermentación en las aceitunas negras maduras en salmuera"-. Grasas y Aceites 26, 297-309.

González Cancho, F., Rejano Navarro, L., Durán Quintana, M. C., Sánchez Roldán, F., García García, P., Castro Gómez-Millán, A. y Garrido Fernández, A. (1983). - "Influencia de la adición de $\mathrm{HCl}$ en la fermentación de aceitunas verdes estilo español»-. Grasas y Aceites 34, 375-379.

González Cancho, F., Rejano Navarro, L., Durán Quintana, M. C., Sánchez Roldán, F., García García, P., Castro Gómez-Millán, A. y Garrido Fernández, A. (1984). - «Elaboración de aceitunas verdes estilo español sin lavados. Solución a los problemas causados por la adición inicial de ácido clorhídrico»-. Grasas y Aceites 34, 375-379.

Juven, B. y Henis, Y. (1970). - «Studies on the antimicrobial activity of olive phenolic compounds»-. J. Appl. Bacteriol. 33, 721-732.

Juven, B., Henis, Y. y Jacoby, B. (1972). - «Studies on the mechanism of the antimicrobial action of oleuropein»-. J. Appl. Bacteriol. 35, 559-567.

Juven, B., Samish, Z. y Henis, Y (1968a). - «Identification of oleuropein as a natural inhibitor of lactic fermentation of green olives"-. Israel J. Agric. Res. 18, 137-138.

Juven, B. Samish, Z., Henis, Y. y Jacoby, B. (1968b). - «Mechanism of enhancement of lactic fermentation of green olives by alkali and heat treatment»-. J. Appl. Bacteriol. 31, 200-207.

Maestro Durán R. y Vázquez Roncero, A. (1976). - “Colorantes antociánicos de las aceitunas manzanillas maduras"-. Grasas y Aceites 27, 237-243.

Marsilio, V., Lanza, B. y Pozzi, N. (1996). - «Progress in table olive debittering. Degradation in vitro of oleuropein and its derivatives by Lactobacillus plantarum»-. JAOCS 73 , 593-597.

McDonald, L. C., Fleming, H. P. y Hassan, H. M. (1990). - Acid tolerance of Leuconostoc mesenteroides y Lactobacillus plantarum»-. Appl. Environ. Microbiol. 56, 2120-2124.

Montaño, A., Bobillo, M. y Marshall, V. M. (1993). -«Effect of sodium chloride on metabolism of two strains of Lactobacillus plantarum isolated from fermenting green olives"-. Letter in Appl. Microbiol. 16, 315-318.

Özay, G. y Borcakli, M. (1995). - «Effect of brine replacement and salt concentration on the fermentation of naturally black olives»-. Food Res. Int. 28, 553-559.

Pelagatti, O. (1978-80). - «La preparazione di olive da tavola verdi al naturale delle varieta nocellara etnea e intosso d'abruzzo»-. Ann. Ist. Sper. Elaiot. VIII, 177-192.

Presidencia del Gobierno (1983). - «Reglamentación técnico sanitaria para la elaboración, circulación, y venta de aceitunas de mesa»-. BOE 108, pp. 1219-1225.

Rejano Navarro, L., Castro Gómez-Millán, A. de, González Cancho, F., Durán Quintana, M. C., Sánchez Gómez, A. H., Montaño Asquerino, A., García García, P., Sánchez Roldán, F. y Garrido Fernández, A. (1986). - «Repercusión de diversas formas de tratamiento con $\mathrm{HCl}$ en la elaboración de aceitunas verdes estilo sevillano»-. Grasas y Aceites 37, 16-24. 
Rodríguez Quiñones, F., Mito, J. J. y Megía, M. (1983). - Estudios fisiológicos y genéticos en lactobacillus plantarum»-. Proceedings II. Reunión de Microbiología industrial. Sevilla, pp. 85-46.

Roig, J. M. y Hernández, J. M. (1991). -«El uso de microorganismos iniciadores, "starters", en la fermentación de aceitunas»-. Olivae 37, 20-28.

Ròzès, N. y Peres, C. (1996). - «Effect of oleuropein y sodium chloride on viability and metabolism of Lactobacillus plantarum"-. Appl. Microbiol. Biotechnol. 45, 839-843.

Ruiz Barba, J. L. (1991). -«Estudio de algunos factores que influyen en el desarrollo de una fermentación ácido láctica apropiada de aceitunas de mesa»-. Tesis Doctoral. Facultad de Biológicas. Universidad de Sevilla.

Ruiz Barba, J. L. y Jiménez Díaz, R. (1994). - Vitamine y amino-acids requirements of lactobacillus plantarum strains from green olive fermentations»-. J. Appl. Bacteriol. 76, 350-355.

Ruiz Barba, J. L. y Jiménez Díaz, R. (1995). -«Availability of essential B-group vitamins to Lactobacillus plantarum in green olive fermentation brines»-. Appl. y Envir. Microbiol. 61, 1294-1297.

Ruiz Barba, J. L., Brenes Balbuena, M., Jiménez Díaz, R. García García, P. y Garrido Fernández, A. (1993). - «Inhibition of Lactobacillus plantarum by polyphenols extracted from two different kind of olive brines»-. J. Appl. Bacteriol. 74, 15-19.

Ruiz Barba, J. L., Garrido Fernández, A. y Jiménez Díaz, R. (1991). - «Bactericidal action of oleuropein extracted from green olives against Lactobacillus plantarum»-. Lett. Appl. Microbiol. 12, 65-68.

Ruiz Barba, J. L., Ríos Sánchez, R. M., Fedriani Irisor, C., Olías Jiménez, J. M. Ríos, J. L. (1990). -«Bactericidal effect of oleuropein extracted form green olives against Lactobacillus plantarum»-. System. Appl. Microbiol. 13, 199-205.

Samish, Z., Cohen, Sh. y Ludin, A. (1968). -«Progress of lactic acid fermentation of green olives as affected by peel»-. Food Technology 22, 1009-1012.
Sánchez, A. H., García, P., Rejano, L., Brenes, M. y Garrido, A. (1995). - «The effects of acidification y temperature during washing of Spanish-style green olives on the fermentation process"-. J. Sci. Food Agric. 68, 197-202.

Sánchez Gómez, A. H., Rejano Navarro, L., Durán Quintana, M. C., Castro Gómez Millán, A., Montaño Asquerino, A., García García, P. y Garrido Fernández, A. (1990). - «Elaboración de aceitunas verdes con tratamiento alcalino y temperatura controlada»-. Grasas y Aceites 41, 218-223.

Sciancalepore, V. (1984). - - La temperatura di deamerizatione nella preparazzione delle olive verdi col sistema Sivigliano"-. Industrie Alimentari 23, 941-944.

Torre, J. E. d. I., Moya, E. R., Bota, E. y Sancho, J. (1993). - Estudio físico-químico y microbiológico de la fermentación de aceitunas verdes arbequinas»-. Grasas y Aceites 44, 274-278.

Van den Borg, D. J. C., Smits, A., Pot, B., Ledeboer, A. M., Kersters, K., Verbakel, M. A., y Verrips, C. T. (1993). - «Isolation, screening y identification of lactic acid bacteria from traditional food fermentation processes $y$ culture collections"-. Food Biotechnology 7, 189-205.

Vaughn, R. H. (1982). - «Table olives, in Industrial Microbiology»-. 4th Edition. Ed. Reeld, G. AVI Publishing Col., Westport, Conneticut, USA.

Vaughn, R. H. Douglas, H. C. y Gililly, J. R. (1943). -«Productions of Spanish type green olives»-. Calif. Agr. Expt. Bull. 678, 1-82.

Vhalov, G. (1990). -Gli antociani polimeri delle olive nere. Loro determinazione in funzione del proceso de maturazione»-. Industrie Alimentari XXIX, gennaio, 1118.

Walter, W. M., Fleming, H. P. y Etchells, J. L. (1973). - «Preparation of antimicrobial compounds by hydrolysis of oleuropein from green olives»-. Appl. Microbiol. 26, 773-776.

Recibido: Junio 1997 Aceptado: Septiembre 1997 